\title{
Caso 6/2007 - Criança de Dez Anos com Estenose Pulmonar Valvar Discreta
}

\author{
Case 6/2007 - A Ten-Year-Old Child with Mild Pulmonary Valve Stenosis
}

Edmar Atik

Instituto do Coração do Hospital das Clínicas - FMUSP - São Paulo, SP - Brasil

\section{Dados clínicos}

Criança de 10 anos de idade, do sexo masculino e de cor branca, com sopro cardíaco auscultado em exame de rotina aos seis meses de idade, mantendo-se assintomática, ativa e sem limitação física. Ao exame físico o paciente estava eupnéico, acianótico, com pulsos normais, peso de $47 \mathrm{~kg}$, altura de $147 \mathrm{~cm}$, pressão arterial de 110/70 mmHg, e freqüência cardíaca de $76 \mathrm{bpm}$. A aorta não foi palpada na fúrcula. No precórdio não havia deformidades ou impulsões e o ictus cordis era localizado no 4o espaço intercostal esquerdo, músculo-valvar +, limitado por uma polpa digital. As bulhas eram normofonéticas, com desdobramento da segunda bulha e com os dois componentes iguais em intensidade. Havia sopro sistólico, de ejeção, $+/++$ de

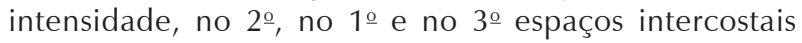
esquerdos, acompanhado de discreto frêmito sistólico. $\mathrm{O}$ fígado não foi palpado.

O eletrocardiograma demonstrou ritmo sinusal com discreta sobrecarga de ventrículo direito, tendo a onda $R$ amplitude de $8 \mathrm{~mm}$ em V1 e com discreto retardo final da condução do estímulo ventricular. SÂP: $+45^{\circ}$; SÂQRS: $+100^{\circ}$; SÂT: $+40^{\circ}$.

\section{Imagem radiográfica}

Imagem demonstrando área cardíaca normal com retificação do arco médio e trama vascular pulmonar normal (fig. 1).

\section{Impressão diagnóstica}

Essa imagem pode corresponder à de um coração normal ou ainda a cardiopatia congênita acianogênica de discreta repercussão.

\section{Diagnóstico diferencial}

Tanto as cardiopatias obstrutivas como as com desvio de sangue da esquerda para a direita, de discreta repercussão, podem se exteriorizar dessa maneira. Difícil é a diferenciação entre a estenose pulmonar valvar e a comunicação interatrial quando ambas se apresentam de grau discreto, sendo necessário invocar outros elementos clínicos.

\section{Confirmação diagnóstica}

O sopro sistólico na área pulmonar acompanhado de frêmito leva ao diagnóstico da estenose pulmonar valvar. A 2 a bulha desdobrada e normofonética expressa a discreta repercussão do defeito, assim como a manifestação tanto eletrocardiográfica (fig. 2) como radiográfica. O ecocardiograma confirmou tal hipótese, com gradiente de pressão entre o ventrículo direito e o tronco pulmonar de $34 \mathrm{mmHg}$. O anel pulmonar tinha 18 $\mathrm{mm}$ de diâmetro e a valva pulmonar era espessa, trivalvular, com discreta dilatação do tronco pulmonar. Outras medidas corresponderam a: diâmetro diastólico do ventrículo esquerdo, $40 \mathrm{~mm}$; aorta, $25 \mathrm{~mm}$; átrio esquerdo, $26 \mathrm{~mm}$; ventrículo direito, $19 \mathrm{~mm}$; septo, $7 \mathrm{~mm}$; e fração de encurtamento da fibra miocárdica, 30\%. O septo atrial era íntegro.

\section{Conduta}

Expectante clínica, em vista da manutenção da magnitude discreta do defeito, com gradiente abaixo de $40 \mathrm{mmHg}$ desde seis meses de idade.

\author{
Palavras-chave \\ Criança, cardiopatias congênitas, estenose da valva \\ pulmonar, sopros cardíacos.
}

Correspondência: Edmar Atik •

InCor - Av. Dr. Enéas de Carvalho Aguiar, 44 - 05403-000 - São Paulo, SP - Brasil E-mail: conatik@incor.usp.br 


\section{Correlação Clínico-Radiográfica}
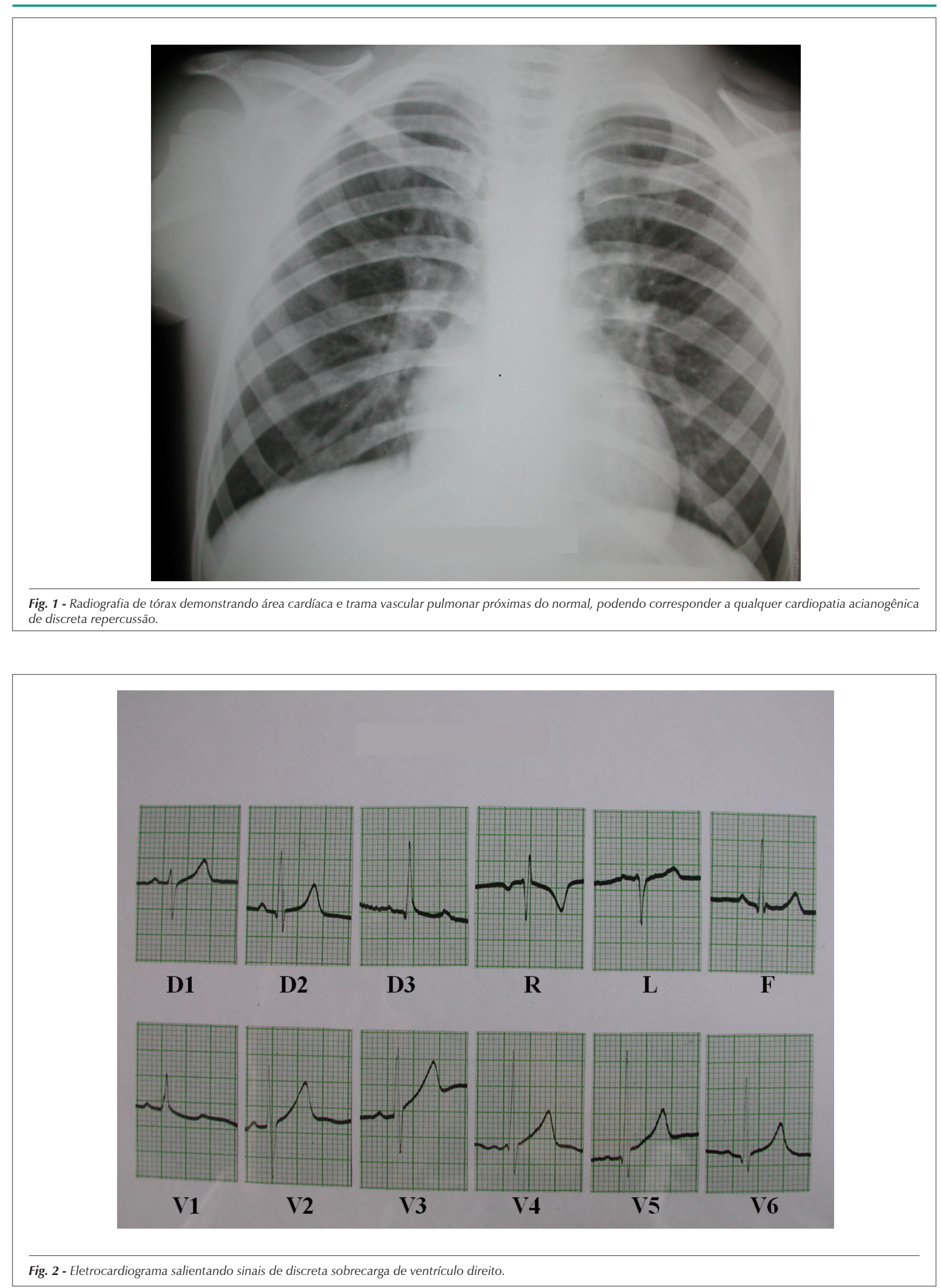